\title{
A Educação a Distância nas Políticas Públicas de Formação Continuada de Professores $^{1}$
}

\author{
Distance Education in Continued Teacher Training Policies \\ L'éducation à Distance Dans Les Politiques de Formation D'enseignants Suivants
}

Daniela de Oliveira Pereira ${ }^{2}$ Universidade Federal de Ouro Preto

\begin{abstract}
Resumo: Este artigo tem como tema as políticas públicas de formação continuada de professores por meio da Educação a Distância - EaD e traz a seguinte questão problema: como as políticas de EaD se constituíram historicamente no Brasil e são implementadas na formação de educadores? Tem-se por objetivo analisar como a modalidade de EaD se inseriu, a partir da Lei de Diretrizes e Bases - LDB de 1996, nas políticas públicas de formação continuada de professores, especialmente nos Planos Nacionais de Educação. Utilizou-se como metodologia a pesquisa bibliográfica, qualitativa e de caráter exploratório, tendo por base autores como Dourado (2008), Belloni (2003), Nogueira (2011), Costa e Zanatta (2010), Pretto e Riccio (2010). O estudo aponta que as mudanças no sistema produtivo mundial influenciaram fortemente as políticas públicas, resultando em reformas para atender a demanda de novos profissionais, inclusive na educação.
\end{abstract}

Palavras-Chave: Educação a Distância. Políticas públicas. Formação continuada. Professor.

Abstract: This article focuses on the public policies of continued education for teachers through Distance Education (EaD in Portuguese) and brings the problem question: how were EaD policies historically constituted in Brazil and how are they implemented in teacher training? The aim of this work is to analyze how the modality of distance education was inserted in public policies of continued teacher training, from the Law of Directives and Bases (LDB in Portuguese), 1996, especially in the National Education Plans. The methodology used was the bibliographical research, both qualitative and exploratory, was used as methodology, based on authors such as Dourado (2008), Belloni (2003), Nogueira (2011), Costa e Zanatta (2010), Pretto e Riccio (2010). The study shows that changes in global productive system strongly influenced public policies, resulting in reforms to meet the demand of new professionals, including in education.

Keywords: Distance Education. Public policies. Continued education. Teacher.

Résumé: Cet article a pour thème les politiques publiques pour la formation continue des enseignants à distance - $\mathrm{EaD}$ et pose la question suivante: Comment les politiques $\mathrm{EaD}$ ontelles été historiquement constituées au Brésil et sont-elles mises en ouvre dans la formation des éducateurs? L'objectif de cette étude est d'analyser la manière dont la modalité EaD a été insérée, sur la base de la Loi sur les directives et les bases - LDB de 1996, dans les politiques publiques pour la formation continue des enseignants, en particulier dans les plans nationaux

\footnotetext{
${ }^{1}$ As reflexões presentes no artigo "A Educação a Distância nas Políticas Públicas de Formação Continuada de Professores" foram abordadas, em parte, em uma publicação no "SIED: EnPED - Simpósio Internacional de Educação a Distância e Encontro de Pesquisadores em Educação a Distância".

${ }^{2}$ Mestre em Educação pelo Programa de Pós-Graduação em Educação da Universidade Federal de Ouro Preto (PPGE/UFOP).E-mail: daniela.ufop@gmail.com. ORCID: https://orcid.org/0000-0002-5185-5020.
} 
d'éducation. Pretto et Riccio (2010) ont été utilisés comme méthodologie de recherche bibliographique, qualitative et exploratoire, à partir d'auteurs comme Dourado (2008), Belloni (2003), Nogueira (2011), Costa et Zanatta (2010). L'étude souligne que les changements intervenus dans le système de production mondial ont fortement influencé les politiques publiques, entraînant des réformes pour répondre à la demande de nouveaux professionnels, y compris dans le secteur de l'éducation.

Mots-clés: Education à distance. Politiques publiques. Formation continue. Professeur

Recebido em: 17 de março de 2019

Aceito em: 21 maio de 2019

\section{Introdução}

As transformações na estrutura produtiva das sociedades capitalistas contemporâneas, impulsionadas pelo avanço tecnológico, criaram novos contextos culturais e novos modos de perceber e de compreender o mundo, além de colocar desafios teóricos e práticos para todas as áreas do conhecimento. Um movimento geral de virtualização, entendida como o movimento em curso, afeta hoje a informação, a comunicação, o funcionamento da economia e várias outras instâncias, inclusive a constituição dos sujeitos. O novo formato social, chamado de sociedade do conhecimento, constitui-se de uma sociedade globalizada, com utilização intensiva do conhecimento através das inovações oferecidas pela informática e pelas novas tecnologias de informação e comunicação - TIC (CASTELLS, 1999). Esse novo modelo é alicerçado na informação e todas as atividades humanas são influenciadas diretamente por ela. Por meio da crescente convergência de tecnologias, os diversos campos do saber tornam-se interligados, transformando a maneira como as atividades são pensadas.

Essas características da sociedade globalizada têm, pois, repercussão direta sobre a educação. As tecnologias que globalizam a informação tendem a se tornar elementos constitutivos dos sistemas educativos. (BELLONI, 2003). Do ponto de vista do processo de ensino-aprendizagem, o novo desafio imposto às instituições de ensino e aos educadores passa a ser o de preparar os sujeitos para desenvolver um conhecimento mais qualificado, autônomo e colaborativo. Nesse sentido, segundo Lévy (1993), é preciso reconhecer um novo estilo de pedagogia que favoreça, ao mesmo tempo, o aprendizado personalizado e o cooperativo em rede. Assim, a função do educador muda radicalmente, ou seja, ele não mais dá aula simplesmente, mas interage sistematicamente com a informação e o conhecimento. $\mathrm{O}$ saber articula-se à nova perspectiva de educação, em função das novas formas de se construir 
conhecimento, que contemplam a democratização do acesso à informação, os novos estilos de aprendizagem e a emergência da inteligência coletiva (LÉVY, 1996, 1999).

Assim, as tecnologias da informação e comunicação - TIC estão cada vez mais presentes, influenciando o modo como as pessoas vivem, pensam e agem, construindo novos códigos de linguagens. Ao mesmo tempo em que essas tecnologias aproximam as pessoas em velocidades cada vez maiores, intensificam-se as exigências e condições para participação, bem como seu potencial de exclusão. Dessa forma, é fundamental que políticas públicas garantam não somente a infraestrutura e o acesso livre à informação, mas, principalmente, a alfabetização e o letramento digital dos diferentes sujeitos sociais para o uso e apropriação das práticas sociais de leitura e escrita, levando-se em consideração que o uso intenso das TIC se constitui como linguagem que precisa ser conhecida, experimentada e ressignificada, a fim de produzir conhecimento.

Diante disso, a Educação a Distância - EaD, como modalidade de ensino, e o uso de suas tecnologias, surge como possibilidade para atendimento das demandas da sociedade que anseia por formação e informação e que busca, ao mesmo tempo, maior desenvolvimento tecnológico, aliado ao rompimento das fronteiras e limites de espaço e tempo. Nesse sentido, esse artigo, que tem como tema central as políticas públicas de formação continuada de professores por meio da Educação a Distância, traz a seguinte questão problema: como as políticas de EaD se constituíram historicamente no Brasil e são implementadas na formação de educadores? Tem-se por objetivo geral analisar como a modalidade de EaD se inseriu, a partir da LDB de 1996, nas políticas públicas de formação continuada de professores.

É importante ressaltar que a reflexão sobre as políticas de EaD permite compreender como se deu o intricado processo de regulamentação dessa modalidade na formação continuada. Tendo isso em mente e visando o alcance do objetivo proposto, utilizou-se como metodologia a pesquisa bibliográfica, qualitativa e de caráter exploratório, tendo por base autores como Dourado (2008), Belloni (2003), Nogueira (2011), Arruda e Arruda (2015), Pesce (2007), Costa e Zanatta (2010), Pretto e Riccio (2010), dentre outros. Dentro dos aspectos metodológicos, optou-se por buscar artigos, dissertações, livros e outras publicações científicas que problematizassem o tema proposto, não ocorrendo a coleta de dados e informações primárias. Os documentos legais, aos quais fazemos referência ao longo desse estudo, serviram de parâmetros e categorias de análises para outros autores e textos que abordaram a formação continuada de professores no contexto da $\mathrm{EaD}$. Assim, procuramos manter, durante toda a análise, diálogo com as produções científicas sobre o tema, a fim de investigar, à luz dos trabalhos que o analisaram, a inserção da EAD nas políticas de formação de professores.

Para fins de organização, primeiramente este trabalho aborda aspectos da regulamentação da modalidade no país e as políticas públicas. Na sequência, analisa-se a forma 
como a Educação a Distância se apresenta no Plano Nacional de Educação - PNE 2001-2011, no Plano de Desenvolvimento da Educação - PDE e no Plano Nacional de Educação - PNE 20142024. E, por fim, busca-se problematizar como as políticas de EaD são implementadas na formação continuada de professores para a expansão do ensino superior.

\section{A regulamentação da Educação a Distância no Brasil e as políticas públicas}

As primeiras manifestações no Brasil para atender o aumento da demanda de alunos nas escolas públicas datam das décadas de 40 e 50, quando as transformações no contex to internacional provocaram mudanças no cenário brasileiro, impulsionando a expansão das indústrias. Entretanto, o Estado, incapaz de acompanhar o ritmo das mudanças econômicas, políticas e sociais, não conseguiu expandir o sistema nacional de educação. Nessa direção, algumas iniciativas foram feitas, como o desenvolvimento radiofônico para a transmissão de programas educacionais, os cursos por correspondência e os programas de teleducação, que formavam profissionais técnicos, voltados ao mercado de trabalho (COSTA e ZANATTA, 2010).

A partir da década de 1980, as transformações econômicas e sociais acarretadas pela universalização do capitalismo modificaram a dinâmica existente, desencadeando várias reformas. Para Souza e Silva (2011), o período de universalização do capitalismo levou a uma reestruturação social que alterou a dinâmica interna do país, provocando reformas institucionais em múltiplos setores, da saúde à educação. Essas mudanças no contexto socioeconômico mundial foram diretamente influenciadas e coordenadas pelas economias centrais do planeta, compostas pelos Estados Unidos e demais membros do Banco Mundial (Banco Internacional para a Reconstrução e Desenvolvimento - BIRD), Fundo Monetário Internacional - FMI e do Banco Interamericano de Desenvolvimento - BID.

Nesse sentido, a intervenção do Estado na economia e na sociedade não está vinculada ao processo democrático, mas é parte do processo produtivo. Reafirmando o que aconteceu nas décadas anteriores, era preciso garantir um mínimo de instrução para os trabalhadores se tornarem úteis e rentáveis ao sistema. Ampliar a educação para todos é também um imperativo econômico para atender às necessidades do sistema. Assim, no Brasil, a partir de 1995, os governos vislumbraram a expansão, democratização e diversificação da oferta do ensino superior por meio da EaD (SANTINELLO, 2014).

Dessa forma, em 1996, a Lei de Diretrizes e Bases - LDB (Lei n. ${ }^{\circ}$ 9.394/1996), em seu artigo 80, passa a tratar a EaD como modalidade de ensino. A partir dessa disposição, cursos e programas em EaD são abertos a partir de um encaminhamento legal e com incentivo do 
Estado. Assim, abre-se a possibilidade da Educação a Distância para além da educação continuada. Para a oferta de cursos, as instituições públicas ou privadas têm que ser credenciadas pelo MEC, que definirá os requisitos e circunstâncias para os exames e registro de diplomas, podendo contar com a integração e cooperação do sistema dos cursos presenciais. Além disso, o rádio e a televisão, que constituíram as primeiras iniciativas de veiculação de programas de EaD no país na década de 40, foram os meios escolhidos, agora regulamentados por lei, como forma de incentivar o desenvolvimento da Educação a Distância no Brasil.

Posteriormente, o artigo 80 da LDB foi regulamentado pelo Decreto 2494/1998, que definiu o que é $\mathrm{EaD}$, dispôs sobre as normas dos programas e possibilitou a criação de novas modalidades de cursos. Entretanto, esse decreto não contemplou todos os setores educacionais, pois não incluiu mestrado, doutorado e nem os cursos que conferem certificado ou diploma de conclusão do Ensino Fundamental, Médio e Superior de graduação, bem como os de educação profissional. O decreto ainda delegou para os demais níveis de ensino a competência para credenciar as instituições que oferecessem a modalidade para a Educação de Jovens e Adultos EJA e Ensino Médio (COSTA e ZANATTA, 2010). No mesmo ano do decreto, foi promulgada a Portaria MEC no 301/1998, que normatizou os procedimentos de credenciamento de instituições para a oferta de cursos de graduação e educação profissional tecnológica a distância.

Várias outras modificações foram sendo introduzidas na legislação. Em 2001, foi criada a Portaria MEC n 2253, que determinou que os cursos superiores poderiam oferecer até $20 \%$ das suas disciplinas utilizando a EaD. No mesmo ano, o Conselho Nacional de Educação CNE elaborou a Resolução CNE/CES nº 01/2001, com normas para o funcionamento dos cursos de pós-graduação lato sensu. Em 2002, o mesmo Conselho estabeleceu as Diretrizes Curriculares Nacionais para a Educação a Distância na EJA e para a educação básica no nível médio. A Portaria MEC n 4059/2004 revogou a Portaria MEC nº 2253/2001 e normatizou os procedimentos para oferta de disciplinas na modalidade não-presencial em cursos de graduação reconhecidos, sejam eles em instituições federais ou não. Essa portaria também prevê o uso integrado de tecnologias, os encontros presenciais e as atividades de tutoria. Ainda em 2004, a Portaria MEC $n^{\circ} 4361$ revogou a Portaria MEC n 301/1998 e incluiu procedimentos para o credenciamento de cursos. Já em 2005, foi promulgado pelo MEC o Decreto $n^{\circ} 5622$, revogando os Decretos $n^{\circ} 2494$ e n $^{\circ}$ 2561/1998 e regulamentando os artigos 80 e 81 da LDB, nas questões de credenciamento e de funcionamento dos cursos de Educação a Distância, além de definir o que se considera como Educação a Distância.

Ainda em relação às mudanças realizadas na legislação, temos o Decreto $\mathrm{n}^{\circ}$ 5800/2006, que instituiu o Sistema Universidade Aberta do Brasil - UAB, com o objetivo de desenvolver a EaD, bem como expandir e interiorizar a educação superior no Brasil. Em 
2007 foi criada a Portaria Normativa ${ }^{\circ}$ 2, definindo os procedimentos de regulamentação e avaliação da educação superior a distância. A Resolução CNE n ${ }^{\circ}$ 01/2007 estabeleceu normas para o funcionamento e oferta dos cursos de pós-graduação lato sensu a distância. Os Referenciais de Qualidade para a Educação Superior a Distância e os instrumentos de avaliação do INEP foram divulgados em 2007 e 2008 pelo MEC e definiram critérios para o credenciamento de instituições, polos e cursos em EaD.

Diante da exigência da LDB de que, até 2007, todos os professores da educação básica deveriam ter curso superior (Política Nacional de Formação de Profissionais do Magistério da Educação Básica) e da impossibilidade da educação presencial atender toda a demanda gerada em virtude disso, o MEC passou a ter como prioridade aprovar e certificar cursos de graduação na modalidade a distância. Assim, nos anos seguintes, foi significativo o crescimento do número de matrículas e de instituições que passaram a oferecer cursos na modalidade EaD. Ao longo desse processo de regulamentação da EaD no Brasil pôde-se perceber que a legislação foi se alterando tanto para o cumprimento das determinações da LDB quanto pela vontade política vinculada aos interesses econômicos e sociais que pressionavam por mudanças.

\section{A Educação a Distância nos Planos de Educação}

Sob o aspecto legal, a EaD foi proposta como modalidade de ensino pela LDB de 1996. Entretanto, de acordo com Nogueira (2011), a EaD já se mostrava incluída no planejamento das políticas públicas brasileiras desde a elaboração do Plano Decenal de Educação para Todos 1993-2003, influenciado pela Conferência Mundial de Educação para Todos, coordenada pela Organização das Nações Unidas para a Educação, a Ciência e a Cultura - UNESCO, pelo Fundo das Nações Unidas para a Infância - UNICEF e pelo Banco Mundial. A Declaração Mundial de Educação para Todos, documento resultante dessa conferência, definia que muitas atividades poderiam ser realizadas de maneira conjunta pelos países, com vistas ao aproveitamento das economias de escala, utilizando-se da EaD para essa forma de colaboração. Assim, o Plano Decenal sugeria a oferta de cursos para alunos que estivessem inseridos no mercado de trabalho e que, por isso, necessitassem de atendimento em regimes especiais de frequência, em tempos e locais diferentes.

Dessa forma, a EaD seria largamente utilizada dentro do modelo fordista, o qual, de acordo com Belloni (2003), se caracteriza, dentre outras coisas, pela otimização dos processos. O Plano ainda propunha a criação do Sistema Nacional de Educação a Distância, visando ampliar o programa de capacitação e atualização dos professores, avaliar os projetos existentes e desenvolver artefatos de apoio à sala de aula. Cabe destacar que algumas ações 
dentro do sistema seriam decorrentes de articulações e recomendações de organismos internacionais (NOGUEIRA, 2011).

Essa primeira ideia de um Sistema Nacional de Educação a Distância esteve presente no projeto inicial da LDB, constituindo-se como diretriz para a modalidade no país. No entanto, Mendes (2005) afirma que a EaD foi reduzida a uma visão resumida e simplista na LDB, dentro de uma concepção neoliberal, sem participação da sociedade civil, já que a formulação e a avaliação das alterações legais posteriores foram centralizadas no Poder Executivo. Outro ponto de análise é que na $\mathrm{LDB}$ não houve preocupação em se definir a $\mathrm{EaD}$, do que se pode inferir a intenção em adaptar a modalidade a interesses específicos do Estado e de organismos internacionais. A autora ainda destaca que a lei deixa implícita a necessidade de um corpo docente especializado e atrelado ao ensino a distância, o que acaba por negligenciar a importância da interação e do diálogo mediado por professores e especialistas em $\mathrm{EaD}$.

3.1 A EaD no Plano Nacional de Educação - PNE 2001-2010

A EaD no PNE 2001-2010 pode ser entendida como uma estratégia de democratização do acesso à educação, principalmente ao ensino superior, por meio da ampliação de vagas e oferta em menor tempo. Entre os objetivos e metas do PNE, encontrase: "estabelecer um amplo sistema interativo de Educação a Distância, utilizando-o, inclusive, para ampliar as possibilidades de atendimento nos cursos presenciais, regulares ou de educação continuada” (BRASIL, 2001, p. 35). Além disso, o PNE prevê um sistema interativo tanto para a modalidade quanto para os cursos presenciais, por meio da ampliação do uso das TIC no ensino superior e na educação básica. É importante destacar que, no texto do Plano, a EaD é tratada como meio auxiliar, o que pode levar a um olhar equivocado da modalidade como solução para os vários problemas históricos relacionados ao acesso ao ensino superior no Brasil (ARRUDA e ARRUDA, 2015). Percebe-se, ao longo do texto, uma ênfase à formação de recursos humanos a distância, por meio de programas de aperfeiçoamento e capacitação, na tentativa de corrigir a defasagem escolar do trabalhador brasileiro, de maneira rápida e com menor custo. Trata-se, pois, de corroborar com a diretriz proposta pelos organismos internacionais da educação permanente ou ao longo da vida.

Nesse sentido, Arruda e Arruda (2015) afirmam que o PNE 2001-2010 refletiu duas abordagens distintas e complementares acerca da EaD: de um lado, um olhar financeiro, referente à ampliação de vagas e redução de custos; de outro, um olhar instrumental e técnico, referente à presença quantitativa de equipamentos, principalmente computadores e televisores, como garantia da melhoria da educação e da possibilidade da oferta de cursos à 
distância. Assim, as reflexões pedagógicas e de organização do trabalho entre os envolvidos no processo de ensino-aprendizagem são reduzidas e simplificadas.

\subsubsection{A EaD no Plano de Desenvolvimento da Educação - PDE}

O PDE, criado em 2007, pode ser entendido como um plano executivo, um conjunto de ações e programas que visam colocar em prática as metas estabelecidas no Plano Nacional de Educação - PNE. O PDE é pautado numa visão sistêmica de que a educação perpassa todos os níveis e modalidades educacionais, como processo de individualização e socialização voltado à construção da autonomia. Constituído por mais de 40 programas, organiza-se em torno de quatro eixos norteadores: educação básica, educação superior, educação profissional e alfabetização (BRASIL, 2007). De modo geral, o PDE aparece como um grande guardachuva que abriga praticamente todos os programas em desenvolvimento pelo MEC. Quanto às modalidades de ensino, as ações previstas no PDE acabam por deixar à margem a maioria das metas previstas no PNE, o que permite afirmar que o PDE foi formulado paralelamente e sem levar em conta o PNE (SAVIANI, 2007).

De acordo com Nogueira (2011), a EaD no PDE apresenta-se nos seguintes programas: Programa Nacional de Informática na Educação (ProInfo), Escola Técnica Aberta do Brasil (e-Tec), Sistema Nacional de Formação de Professores: nova CAPES e UAB; Pró-Funcionário e Pró-Letramento. Assim, percebe-se, mais uma vez, que a Educação a Distância aparece em programas voltados ao aperfeiçoamento e capacitação. Nesse sentido, assim como no texto do PNE 2001-2010, Saviani (2007) analisa que a EaD é tratada como auxiliar no processo educativo, inclusive em cursos de formação de professores. Entretanto, tomá-la como base principal pode se tornar um problema, uma vez que se corre o risco de transformar a modalidade num mecanismo de certificação, sem a efetiva qualidade.

3.2 A EaD no Novo Plano Nacional de Educação - PNE 2011-2020

A Conferência Nacional de Educação - CONAE, realizada em 2010, apresentou em seu documento final as diretrizes, metas e ações para a política nacional de educação, que deveriam constituir o novo Plano Nacional de Educação. Em tal documento, a EaD aparece no Eixo IV - Formação e Valorização dos Profissionais da Educação, representando a continuidade da EaD em processos formativos (NOGUEIRA, 2011). A esse respeito, o documento referência da CONAE, que posteriormente serviria de base para as discussões nas Conferências Estaduais e Municipais de Educação, afirma que: 
Como consequência de uma política nacional de formação e valorização dos/das profissionais da educação, a formação inicial deve ser articulada com a formação continuada, envolvendo todas as licenciaturas e estabelecendo o formato presencial ou a distância que cada projeto específico poderá conformar (...) (BRASIL, 2010, p. 62).

O texto da conferência ainda relata que a formação inicial pode ocorrer na modalidade $\mathrm{EaD}$, de forma excepcional, para os professores em exercício, nos locais onde não existam cursos presenciais. A partir desse enunciado, Nogueira (2011) levanta um questionamento de que esse caráter de excepcionalidade poderia vir a ser a indicação de continuidade dos cursos de formação inicial à distância e, portanto, da UAB. Além disso, destaca-se a necessidade de se firmar políticas contrárias aos cursos de má qualidade bem como a valorização do papel do professor no processo de ensino a distância. $\mathrm{O}$ documento ainda faz referência à oferta de cursos técnicos de atualização bem como à EJA, dentro da perspectiva da educação ao longo da vida.

O novo PNE, resultante de idas e vindas e várias discussões, acabou por definir a função da EaD para o período de 2014-2024, relacionando-a à educação de jovens e adultos, à educação profissional e à formação continuada dos profissionais da educação. Entretanto, o PNE não menciona de maneira explícita a $\mathrm{EaD}$, utilizando-se somente dos termos "plataforma eletrônica" e "modernas tecnologias de informação e comunicação" (ZANLORENZI, 2015).

\section{Formação Continuada de Professores e a Expansão do Ensino Superior a Partir da Educação a Distância}

A partir de 1993, o governo federal deu início a medidas para a formulação de uma política de EaD. Dentre essas medidas, pode ser mencionado o Acordo de Cooperação Técnica $\mathrm{n}^{\circ}$ 4/1993, firmado entre o MEC e a Universidade de Brasília, para coordenação de um Consórcio Interuniversitário de Educação Continuada e a Distância - BRASIL EaD. Tal consórcio teve como objetivo dar suporte à educação básica, tendo em vista a carência de professores habilitados para todos os níveis de ensino. Um ano depois, em 1994, o MEC instituiu o Sistema Nacional de EaD - SINEaD, que emergiu para apoiar o Plano Nacional de Educação para Todos, visando a erradicação do analfabetismo e a universalização do ensino fundamental. Já em 1996, além da LDB que regulamentou a EaD como modalidade de ensino, foi criada a Secretaria de Educação a Distância - SEED, que passou a rever e a normatizar os convênios firmados anteriormente no SINEaD (SARDELICH, 2013). Desde então, devido a exigências legais e à falta de profissionais devidamente formados para atuarem nos sistemas de ensino, vários programas têm sido formulados para a formação 
emergencial de professores: Programa Especial de Formação Pedagógica - Resolução CNE n 2/1997; Programa Pró-licenciatura; Sistema Universidade Aberta do Brasil - UAB; Programa de Formação Inicial e Continuada, Presencial e a Distância, de Professores para a Educação Básica - PARFOR; Programa Nacional de Formação Continuada em Tecnologia Educacional - PROINFO INTEGRADO; e, mais recentemente, com implantação prevista para 2016, a Rede Universidade do Professor.

Ao se tratar da temática sobre formação continuada de professores no Brasil, percebese a expansão avassaladora da EaD no ensino superior como resposta à necessidade de democratização e ampliação do acesso à educação. Porém, vê-se que, em muitos momentos, a discussão sobre a educação propriamente dita é relegada a segundo plano. As políticas públicas adotaram o ensino a distância como principal estratégia para ampliação da oferta, tanto no ensino público quanto no privado.

Problematizar as questões que advêm desse cenário torna-se cada vez mais urgente, principalmente com a emergência da cibercultura, que desafia currículos e docentes com possibilidades de socialização, aprendizagem colaborativa e interatividade, mediadas pelo ciberespaço. Assim, emerge a necessidade de formação de relações de ensino-aprendizagem diferentes, em que as informações sejam ressignificadas para serem transformadas em conhecimento. Nesta sociedade do conhecimento, os sujeitos devem estar dispostos a aprender a aprender constantemente, cada vez mais e das mais variadas maneiras. Portanto a educação, na tentativa de assimilar mudanças e necessidades da contemporaneidade, tende a se transformar para refletir as exigências e perspectivas que as tecnologias, a globalização e o mundo do trabalho impõem.

Diante dessa perspectiva, cabe o entendimento da formação continuada de professores como inerente à própria atividade educativa. Tal atividade assume, cada vez mais, dimensões significativas, diante da presença generalizada das TIC em toda a sociedade, como novas práticas de comunicação praticamente instantâneas. É preciso pensar, portanto, numa rede de formação e aprendizagem que ultrapasse a mera transmissão de informações e que articule as tecnologias digitais. Há, pois, uma nova forma de pensar e de produzir conhecimento que traz novos elementos para a educação (PRETTO e RICCIO, 2010).

A apropriação dessas tecnologias pelos professores no ensino superior e na educação básica, para além da mera incorporação instrumental, requer a adoção de políticas públicas que possibilitem a conexão de estudantes, docentes e demais atores sociais, em qualquer tempo e espaço, por meio das TIC. A partir da formação dessa sociedade conectada, é possível pensar num processo de formação continuada na modalidade $\mathrm{EaD}$, estabelecido a 
partir de bases conceituais como a noção de tecnologia, a ideia de cibercultura, a globalização e os ambientes virtuais de aprendizagem.

Além disso, os programas de formação continuada de educadores em ambientes digitais precisam considerar as circunstâncias históricas, não se reduzindo apenas às necessidades do sistema produtivo. É necessário considerar os professores como sujeitos sociais e proporcionar-lhes a oportunidade de desenvolver o diálogo, a autonomia, a crítica e a reflexão sobre sua própria atividade. Deve-se pensar na formação de educadores por meio de práticas que promovam ressignificações e prepará-los para lidar com flexibilidade diante das transformações tecnológicas que surgem de maneira incessante (PESCE, 2007).

De modo geral, observa-se que as políticas de formação continuada não seguem uma continuidade, uma vez que cada governo altera ou interrompe os projetos e atividades. Assim, ao invés dos programas de $\mathrm{EaD}$ possibilitarem formação e emancipação, eles acabam por estarem a serviço das políticas educacionais oriundas das orientações de organismos internacionais e dos princípios neoliberais. Dessa forma, o Estado investe em projetos de Educação a Distância tentando solucionar, de maneira rápida, o problema maior da formação de professores.

Como afirma Dourado (2008), o Brasil vive um complexo processo de expansão da educação básica e superior, que impõe grandes desafios à garantia do acesso e da qualidade da educação em todos os níveis e modalidades. Nesse processo de expansão, destacam-se as políticas voltadas para a formação de professores que nem sempre foram orientadas para organização e qualidade, traduzindo-se por ações superpostas e contraditórias, características das políticas emergenciais. Assim, a EaD tem se constituído como um espaço de efetiva expansão da educação superior brasileira, tanto nas instituições públicas quanto nas privadas. Entretanto, é preciso fazer emergir o questionamento de alguns argumentos, tais como a adesão acrítica à implementação da EaD, tendo como centro o aparato tecnológico, negligenciando as condições e os envolvidos no processo de ensino-aprendizagem.

\section{Considerações Finais}

Desde a década de 90, a sociedade tem assistido a uma verdadeira revolução tecnológica. As instituições de ensino superior passaram a desenvolver cursos a distância, utilizando as TIC, a fim de promover a expansão e a democratização da educação. Apesar da $\mathrm{LDB}$ ter regulamentado a $\mathrm{EaD}$ como modalidade de ensino e legislações posteriores terem revisado pontos importantes da lei básica, a formação continuada de educadores por meio da $\mathrm{EaD}$, apesar de indiscutíveis benefícios, precisa ser observada com cautela, principalmente quanto à qualidade dos materiais didáticos utilizados e aos processos de avaliação. 
É fato que as políticas educacionais devem se preocupar com a universalização das oportunidades de acesso à educação. No entanto, a democratização não pode ser sinônimo de uma formação aligeirada, mas deve, primordialmente, ater-se a uma educação que promova a emancipação dos sujeitos enquanto atores sociais. Os programas de formação continuada de educadores via $\mathrm{EaD}$ devem permitir a compreensão e apropriação crítica das tecnologias da contemporaneidade, com a produção, ressignificação e divulgação do conhecimento. Dessa forma, esses programas podem vir a desmistificar para os professores a questão dos artefatos tecnológicos como obstáculos, e torná-los recursos que potencializam o processo de ensino-aprendizagem.

Retomando o objetivo e a questão central que permearam esse estudo, algumas considerações se fazem necessárias. A apropriação das tecnologias pelos professores no Ensino Superior e na Educação Básica, mais que mera incorporação instrumental, requer a adoção de políticas públicas que possibilitem a conexão de alunos, docentes e demais atores sociais, em qualquer tempo e espaço, por meio das tecnologias digitais de informação e comunicação - TDIC. Nesta sociedade do conhecimento, conectada em rede, é possível pensar em formação continuada na $\mathrm{EaD}$, com bases conceituais como a noção de tecnologia, a ideia de cibercultura, a globalização e os ambientes virtuais de aprendizagem.

Nessa perspectiva, os programas de formação continuada de professores por meio da EaD devem considerar as circunstâncias históricas, não se reduzindo apenas às necessidades do sistema produtivo. É necessário considerar os professores como sujeitos sociais e proporcionar-lhes a oportunidade de desenvolver o diálogo, a autonomia, a crítica e a reflexão sobre a própria atividade. Deve-se pensar na formação de professores por meio de práticas que promovam ressignificações e prepará-los para lidar com a flexibilidade diante das transformações tecnológicas que surgem de maneira incessante (PESCE, 2007).

Entretanto, de modo geral, o que se pode observar é que as políticas de formação continuada não são perenes, uma vez que cada governo altera ou interrompe projetos. Assim, em vez de programas de EaD possibilitarem formação e emancipação, acabam por estar a serviço das políticas educacionais oriundas das orientações de organismos internacionais e dos princípios neoliberais. Dessa forma, o Estado investe em projetos de $\mathrm{EaD}$ tentando solucionar, de maneira rápida, o problema maior da formação de professores. Apesar de a LDB ter regulamentado a $\mathrm{EaD}$ como modalidade de ensino e de legislações posteriores terem revisado pontos importantes da lei básica, a formação continuada de professores por meio da $\mathrm{EaD}$, mesmo com indiscutíveis benefícios, tem de ser observada com cautela, principalmente quanto à qualidade dos materiais didáticos utilizados e aos critérios de avaliação.

Por fim, cabe ressaltar que as metas e objetivos descritos nos planos nacionais de educação, que traduzem a mera preocupação de expandir a educação pública no país a qualquer 
preço, acabam por se tornar somente parâmetros e referenciais inalcançáveis. Ou, o que é pior, constituem-se apenas como números que, na prática, pouco colaboram para a melhoria da educação no país. Ora, as políticas de formação inicial e continuada de professores para os vários níveis e modalidades de ensino não podem ser resultado de vontades políticas nem se pautar em financiamentos instáveis e descontinuados. A EaD não pode, de maneira nenhuma, se prestar ao papel de promover uma expansão da educação pautada pelo atendimento quantitativo recomendado por órgãos internacionais como o Banco Mundial, o BID, o FMI e outros. Para além de uma formação de baixo custo e aligeirada, é necessário que a Educação a Distância se constitua a partir de uma política sólida bem como de um amplo processo de institucionalização, que negue o caráter provisório e emergencial voltado para a resolução rápida de uma demanda por mão-de-obra qualificada.

\section{Referências}

AGUIAR, S.F. de As Políticas Públicas Educacionais do Governo Lula e a Educação a Distância. Dissertação de mestrado. Belo Horizonte: Centro Federal de Educação Tecnológica de Minas Gerais, 2012. Disponível em: < http:// www.files.scire.net.br/atrio/cefetmg.../sabrina_ferreira_de_aguiar $>$ Acesso em $27 \quad$ dez. 2015 . https://doi.org/10.14295/2596-2221.xviceel.2018.139

ARRUDA, E. P. ARRUDA, D. E. P. Educação a Distância no Brasil: Políticas Públicas e Democratização do Acesso ao Ensino Superior. Educação em Revista, Belo Horizonte, v. 31, n. 03, 2015. Disponível em: < http:// http://www.scielo.br> Acesso em 07 jan. 2016. https://doi.org/10.1590/0102-4698117010

BELloni, M. L. Educação a Distância. Campinas: Autores Associados, 2003.

BRASIL. Conferência Nacional de Educação - CONAE. Construindo o Sistema Articulado de Educação: Plano Nacional de Educação, Diretrizes e Estratégias de Ação - Documento Referência. Brasília: Ministério da Educação, 2010. Disponível em: < http://portal.mec.gov.br/arquivos/pdf/conae/documento_referencia.pdf> Acesso em 15 mai. 2019. https://doi.org/10.1590/s0101-73302010000300019

BRASIL. Lei $n^{\circ}$ 9394, de 20 de dezembro de 1996. Lei de Diretrizes e Bases da Educação Nacional: Estabelece as diretrizes e bases da educação nacional. Disponível em: < http://portal.mec.gov.br/arquivos/pdf/ldb> Acesso em 12 dez. 2015. https://doi.org/10.11606/d.7.2013.tde-10092013-151829

BRASIL. Lei $n^{\circ}$ 10172, de 09 de janeiro de 2001. Plano Nacional de Educação. Disponível em: $<$ http://www.planalto.gov.br/ccivil_03/leis/leis_2001/110172.htm> Acesso em 12 dez. 2015. https://doi.org/10.1590/s0104-40602006000100015

BRASIL. Plano de Desenvolvimento da Educação. Brasília: Ministério da Educação, 2007. Disponível em: < http://portal.mec.gov.br/arquivos/livro/livro.pdf> Acesso em 12 dez. 2015. https://doi.org/10.11606/d.8.2013.tde-18092013-111030 
CASTELLS, M. A Sociedade em Rede - a Era da Informação: Economia, Sociedade e Cultura. São Paulo: Paz e Terra, 1999. https://doi.org/10.17231/comsoc.5(2004).1256

COSTA, M. L. F. ZANATTA, R. M. (orgs.) Educação a Distância no Brasil: Aspectos Históricos, Legais, Políticos e Metodológicos. 2. ed. Maringá: Eduem, 2010.

DOURADO, L. F. Políticas e Gestão da Educação Superior a Distância: Novos Marcos Regulatórios? Educação \& Sociedade, Campinas, v. 29, n. 104, p. 891-917, out. 2008. Disponível em: <http://www.cedes.unicamp.br> Acesso em 05 jan. 2016. https://doi.org/10.1590/s0101-73302008000300012

LÉVY, P. Cibercultura. Rio de Janeiro: Editora 34, 1999.

LÉVY, P. O que é o Virtual? Rio de Janeiro: Editora 34, 1996. COLOCAR OS NOMES DOS AUTORES

LÉVY, P. As Tecnologias da Inteligência: O Futuro do Pensamento na Era da Informática. Rio de Janeiro: Editora 34, 1993.

MENDES, A. M. A Educação a Distância nos Meandros da Legislação Brasileira: 1988-1996. Dissertação de mestrado. Brasília: Faculdade de Educação, Universidade de Brasília, 2005. Disponível em: < http:// www.unb.br> Acesso em 27 dez. 2015. https://doi.org/10.20873/uft.rbec.v4e6291

NOGUEIRA, D. X. P. A Educação a Distância no Brasil: da LDB ao Novo PNE. In: $25^{\circ}$ Simpósio Brasileiro e $2^{\circ}$ Congresso Ibero-Americano de Política e Administração da Educação, 2011, São Paulo. Comunicação. São Paulo, 2011, PUC-SP e USP. Disponível em: $<\quad$ http://www.anpae.org.br/simposio2011>. Acesso em: 18 dez. 2015. https://doi.org/10.29381/0103-8559/2019290143-5

PESCE, L. As Contradições da Institucionalização da Educação a Distância, pelo Estado, nas Políticas de Formação de Educadores: Resistência e Superação. HISTEDBR On-line, Campinas, n.26, p.183-208, jun. 2007. Disponível em: <http:// histedbr.fe.unicamp.br> Acesso em 05 jan. 2016. https://doi.org/10.20396/rho.v15i65.8642710

PETERS, O. Didática da Educação a Distância. São Leopoldo: Unisinos, 2001.

PRETTO, N. L. RICCIO, N. C. R. A Formação Continuada de Professores Universitários e as Tecnologias Digitais. Educar, Curitiba, n. 37, p. 153-169, maio/ago. 2010. Disponível em: <http://www.scielo.br> Acesso em 05 jan. 2016. https://doi.org/10.1590/s0104$\underline{40602010000200010}$

SANTINELlo, J. Pressupostos Teóricos da Educação a Distância no Brasil. EmRede - Revista de Educação a Distância UniRede, Santa Catarina, v. 1, n.1, 2014. Disponível em <www.aunirede.org.br > Acesso em 07 jan. 2016. https://doi.org/10.3895/rbect.v8n2.2974

SARDELICH, M. E. Formação de Professores no Brasil: Políticas para a Modalidade a Distância. Educação em Foco, Belo Horizonte, v. 16, n. 22, p. 13-43, dez. 2013. Disponível em <www.uemg.br> Acesso em 20 mai. 2016. https://doi.org/10.1590/1983-21172008100103 
SAVIANI, D. O Plano de Desenvolvimento da Educação: Análise do Projeto do MEC. Educação \& Sociedade, Campinas, v. 28, n. 100, p. 1231-1255, out. 2007. Disponível em: <http://www.cedes.unicamp.br> Acesso em 05 jan. 2016. https://doi.org/10.1590/s010173302007000300027

SOUZA, M. M. P. de. SILVA, W. V. K. M. Fundamentos Históricos da Educação a Distância: Políticas e Práticas da EaD no Brasil. Maringá: CESUMAR, 2011.

ZANLORENZI, M. J. Entre a LDB 9.394/96 e o PNE 2014-2024: Breves Apontamentos Sobre a Educação a Distância na Formação de Professores. In: Encuentro Latinoamericano de Profesores de Política Educativa, II Seminário Internacional de Questões de Pesquisa em Educação, 2015, Guarulhos - SP. Comunicação. Guarulhos, 2015, UNIFESP. Disponível em $<\quad$ http://www.relepe.org $>\quad$ Acesso em $07 \quad$ jan. 2016. https://doi.org/10.17143/ciaed/xxiiciaed.2016.00056 